\title{
Cloning and Expression of FixA and FixB Genes and Their Role in the Formation of Dipicolinic Acid in Mycobacterium marinum CCUG 20988
}

\author{
Mohammad Faezi Ghasemi ${ }^{1, *}$; Fredrik Pettersson ${ }^{2}$; Leif Kirsebom ${ }^{2}$ \\ ${ }^{1}$ Department of Microbiology, Faculty of Basic Sciences, Lahijan Branch, Islamic Azad University, Lahijan, IR Iran \\ ${ }^{2}$ Department of Cell and Molecular Biology, Biomedical Center, Uppsala University, Uppsala, Sweden \\ ${ }^{*}$ Corresponding author: Mohammad Faezi Ghasemi, Department of Microbiology, Faculty of Basic Sciences, Lahijan Branch, Islamic Azad University, Lahijan, IR Iran. \\ E-mail: faezi_m@yahoo.com
}

Received: February 26, 2014; Accepted: May 8, 2014

\begin{abstract}
Background: Dipicolinic acid (DPA) comprising 5-15\% of the spore dry weight is important for spore stability and resistance properties. In some Gram-positive bacteria such as Clostridium perfringens, an electron transfer flavoprotein, EtfA, acts in an incorporative way in DPA formation.

Objectives: The aim of this study was to explore if the fixA and fixB genes which are electron transfer flavoproteins could incorporate in DPA formation in Mycobacterium marinum CCUG 20988.

Materials and Methods: In this descriptive-analytic study, the fixA and fixB genes were PCR-amplified and ligated between the Nde I and Hind III sites of pET19b vector with ampicillin resistance gene in frame with an N-terminal T7-promotor and a C-terminal of 6-histidin tag and transformed into BL21-Codon Plus-RIL Escherichia coli competent cells. For over expression of fixA and fixB genes, SDS-polyacrylamide gel electrophoresis was used. Also the direct interaction between dihydrodipicolinate acid (DHDPA) synthase and fixA and fixB proteins for DPA formation was investigated.

Results: Detectable DPA formation has been identified upon isopropyl-p-D-thiogalactopyranoside (IPTG) induction using fixA and fixB genes together. The amount of dipicolinic was about 32.8 and $49.2 \mu \mathrm{g} / \mathrm{mL}$ acids in LB and M9 media, respectively.

Conclusions: It can be concluded that both fixA and fixB genes as electron transfer flavoproteins may incorporate in dipicolinic acid formation in M. marinum. We assume that if sporulation turns out to be a common mechanism used by mycobacteria in response to environmental conditions, it might be one of the means by which it attains dormancy within the host.
\end{abstract}

Keywords: Mycobacterium marinum; Dipicolinic acid; FixA protein; Spore formation

\section{Background}

Dipicolinic acid (DPA) is a major component of bacterial exospores, comprising 5-15\% of the spore dry weight; therefore, important for spore stability and resistance properties [1]. In low guanine-cytosine content $(\mathrm{G}+\mathrm{C})$ group of Gram-positive bacteria such as Bacillus subtilis, DPA is produced during late stage sporulation via a branch off of the lysine biosynthetic pathway. One step in this pathway is catalyzed by dihydro-dipicolinate synthase (DHDPA synthase), which is encoded by dapA [2, 3]. DHDPA synthase has long been thought to condense aspartate semialdehyde (L-ASA) and pyruvate to produce dihydrodipicolinic acid (DHDPA) [4]. Studies have suggested that the product of DHDPA synthase is not dihydrodipicolinic acid but rather 4-hydroxy-tetra-hydro-dipicolinic acid, which undergoes spontaneous dehydration to DHDPA [5]. Production of DPA from L-ASA and pyruvate in vitro has been accomplished with sporulating Bacillus megaterium cell extract [6] requiring the presence of both a DHDPA synthase and a DPA synthase. The latter enzyme is the product of the spoVF operon which encodes two products; spoVFA encodes a putative dehydrogenase while spoVFB appears to be a flavoprotein. Inactivation of either gene in B. subtilis resulted in loss of DPA production, and expression of both genes in Escherichia coli under conditions that induce lysine biosynthesis resulted in DPA synthesis certain clostridia lack spoVF operon and generate dipicolinic acid via an electron transfer flavoprotein that is widely distributed among both endosporeforming and non nonendospore-forming bacteria [3].

The genus Mycobacterium includes highly successful pathogens such as Mycobacterium tuberculosis and Mycobacterium leprae, the etiological agents of tuberculosis and leprosy [7]. Recently, Ghosh et al. reported that species of M. marinum produce a type of spore known as endospore. This discovery is potentially significant in medicine, because it is a definition for latency paradigm in Mycobacterium genus. M. marinum is a close genetic relative of $M$. tuberculosis, and it has emerged as an attractive model system to identify and study factors important for infection disease development and resistance of M. tuberculosis [7].

Copyright (C) 2015, Zahedan University of Medical Sciences. This is an open-access article distributed under the terms of the Creative Commons Attribution-NonCommercial 4.0 International License (http://creativecommons.org/licenses/by-nc/4.0/) which permits copy and redistribute the material just in noncommercial usages, provided the original work is properly cited. 
Faezi Ghasemi M et al.

Endospores contains numerous molecules such as proteins in protective shell (called the coat), a family of DNA-protective proteins known as small acid soluble proteins known as small acid soluble protein (SASP) that are bound to chromosome, and a unique small molecule, dipicolinic acid [8]. All previously known examples of endospore-forming bacteria are members of the low $\mathrm{G}+\mathrm{C}$ group of Gram-positive bacteria (Firmicutes) belonging either to Bacilli or to Clostridia and in all cases in which a genome sequence is available, orthologs genes involved in endospore formation are readily seen. The Mycobacterium genus is a member of high $\mathrm{G}+\mathrm{C}$ group of Grampositive bacteria (Actinobacteria) for which there are no claims of endospore formation. Certain members of the group, such as Streptomyces, do produce spores, but spores, are fundamentally different kinds that are not produced inside a mother cell [9].

Reporting the formation of endospore in genus Mycobacterium is significant in biology of these bacteria, so finding new supporting data to prove this claim is very important. In this study we explore if the fixA and fixB genes which are electron transfer flavoproteins may incorporate in DPA formation in M. marinum T CCUG 20988. FixA (ID: 887670), is an electron transfer flavoprotein (beta-subunit) with locus tagsMMAR1684 and Rv3029c in M. marinum and M. tuberculosis H37 Rvgenomes, and encodes a protein with 263 amino acids in nitrogen metabolism pathway. Also, fixB (ID: 6225942), is an electron transfer flavoprotein (alpha-subunit) with locus tag MMAR1685 in M. marinum M genome and encodes a protein with 318 amino acids in nitrogen metabolism pathway. At first, the expression of fixB gene was studied separately. Then fixA and fixB genes expressions were evaluated both together in BL21-Codon Plus-RIL E. coli.

\section{Materials and Methods}

In this descriptive-analytic study, all media and materials used were obtained from (Sigma-Aldrich). The strain of M. marinum CCUG 20988 was obtained from Culture Collection University of (CCUG, Goteborg, Sweden). BL21CodonPlus-RIL E. coli obtained from Stratagene (Stratagen, California, USA) and pET19b vector was obtained from Novagen (Novagen, Medison, USA).

M. marinum T CCUG 20988 genomic DNA was extracted using the protocol suggested by Evgen Benedik 2010. The fixA (ID: 887670) and fixB gene (ID: 6225942) was PCRamplified and ligated between the Nde I and Hind III sites of pET19b vector with ampicillin resistance gene in frame with an N-terminal T7-promotor and a C-terminal of 6-histidin tag. The sequences of forward and reverse primers for fixB amplification were (5'-TTTTCATATGGCTGA AGTATTGGTCG-3') and (5'-TTTGGATCCTCAGCCCT TGCGAGCCTTG-3'), respectively. The results for plasmid construction for fixB gene amplified with, were confirmed using FP0942 and FP0943 external primers. For amplification of fixB gene, the following PCR protocol was used: initial denaturation at $98^{\circ} \mathrm{C}$ for 3 minutes, fol- lowed by 30 cycles of $98^{\circ} \mathrm{C}$ for $15 \mathrm{sec}, 50^{\circ} \mathrm{C}$ for $30 \mathrm{sec}$, and $72^{\circ} \mathrm{C}$ for 1 minutes, with a final extension $72^{\circ} \mathrm{C}$ for 5 minutes. For amplification of fixA and fixB genes together, the following PCR protocol was used: initial denaturation at $98^{\circ} \mathrm{C}$ for 3 minutes, followed by 35 cycles of $98^{\circ} \mathrm{C}$ for 30 sec, $55^{\circ} \mathrm{C}$ for 1 minutes and $72^{\circ} \mathrm{C}$ for 1 minutes, with a final extension $72^{\circ} \mathrm{C}$ for 10 minutes. The reaction mixture for the amplification was performed in $1 \mathrm{~mL}$ Eppendorf tubes containing: $\mathrm{H}_{2} \mathrm{O}_{2} 285 \mu \mathrm{L}, 5 \mathrm{X}$ buffer $100 \mu \mathrm{L}$, dNTPs 10 $\mu \mathrm{L}$, forward and reverse primers $25 \mu \mathrm{L}$, template DNA $5 \mu \mathrm{L}$ and DNA polymerase $5 \mu \mathrm{L}$. Sequencing of amplified genes was performed by Macrogen Co. Ltd. (South Korea). The recombinant plasmid was transformed into BL21-CodonPlus-RIL E. coli competent cells. The cells were grown in Luria Bertani (LB) medium at $37^{\circ} \mathrm{C}$ to an OD600 of 2.0 and fixB expression induced with $1 \mathrm{mM}$ IPTG for 2 hours. BL21CodonPlus-RIL E. coli containing pknB gene was used as a negative control for IPTG induction. For IPTG induction of the recombinant strains, a single colony of each strain was cultured in LB medium containing ampicillin and incubated at $37^{\circ} \mathrm{C}$ for an overnight. One hundred microliter of overnight cultures were transferred into $25 \mathrm{~mL}$ of fresh LB medium and incubated until the cell density reached to (0.40-0.5.0 OD600). Then $100 \mu \mathrm{L}$ of $1 \mathrm{M}$ IPTG was added to the medium and the incubation continued for 2 hours.

The Janssen et al. [10] method was used for estimation of dipicolinic acid. For DPA estimation 5 mL BL21-CodonPlus-RIL E. coli recombinant cells grown in LB medium (0.8-1.0 OD600) were autoclaved at 15 pounds per square inch (Ib/in2) for 15 minutes. Then the lysate was cooled, acidified with $0.1 \mathrm{~mL}$ of $1.0 \operatorname{Normal}(\mathrm{N})$ acid acetic and left at room temperature for 1 houre and clarified by centrifugation at $1500 \mathrm{~g}$ for 10 minutes. This was followed by the addition of freshly prepared ferrous ammonium sulfate hexahydrate and the color was measured at $440 \mathrm{~nm}$. A calibration curve, prepared by using standard solution of pure DPA (Sigma-Aldrich) in distilled water, was used to calculate the amount of DPA in the clear lysate. Spore suspension of Bacillus subtilis 168 grown in LB medium was used as positive control. Statistical analysis was performed using Microsoft office excel 2010 for determination of DPA concentrations in experimental trials.

The L-aspartate $\beta$-semialdehyde (L-ASA) was synthesized by the method of Black and Wright [11]. Samples were removed throughout the ozonolysis procedures, neutralized with $1 \mathrm{M} \mathrm{NaHCO}_{3}$ and subjected to mass analysis with an ABI-3200 mass spectrometer. The reaction was terminated when the peak corresponding to deprotonated mass (M-H) of L-allylglycine, 114.1, was confirmed by production of DPA by a crude cell extract of sporulating B. subtilis wild-type strain 168 . The L-ASA solution was aliquoted and stored at $-80^{\circ} \mathrm{C}$.

SDS-Polyacrylamide gel electrophoresis was used in order to study the over expression of fixA and fixB genes in cell extract of BL21-CodonPlus-RIL E. coli. For preparation of cell extraction, the fermentation broth were centrifuged at 14000 RPM and the pellets were resuspended in 
$5 \mathrm{~mL}$ phosphate buffer and centrifuged at $14000 \mathrm{RPM}$, supernatant decanted and resuspended in $100 \mu \mathrm{L}$ phosphate buffer and sonicated three times for $15 \mathrm{sec}$. The standard curve has been made with bovine serum albumin (BSA) using Bradford protein assay method. Molecular weight size marker obtained from Sigma-Aldrich Co. Ltd.

Expression of DPA synthase was investigated in M9 minimal medium containing proline and thiamin. To prepare M9 minimal medium: $100 \mathrm{~mL}$ of 5xM9 salts, $5 \mathrm{~mL}$ of $10 \%$ glycerol, $1 \mathrm{~mL}$ of $1 \mathrm{M} \mathrm{MgSO}_{4}, 50 \mu \mathrm{L}$ of $1 \mathrm{M} \mathrm{CaCl}_{2}, 5 \mathrm{~mL} 100 \mathrm{x}$ thiamin solution, $2.5 \mathrm{~mL}$ of filter sterilized $\mathrm{NH}_{4} \mathrm{Cl}(0.2 \mathrm{~g}$ ) $\mathrm{mL}), 10 \mathrm{~mL} 20 \%$ d-glucose and $2.5 \mathrm{~mL}$ of $200 x$ proline solution were mixed and prepared to final volume of $500 \mathrm{~mL}$ and autoclaved at $15 \mathrm{Ib} / \mathrm{in}^{2}$ for 15 minutes.

The system for determining DPA synthase activity was modified from that of Bach and Gilvarg [6]. The total reaction of $2 \mathrm{~mL}$ contained $3 \mathrm{mg}$ of total protein and $10 \mathrm{mM}$ sodium pyruvate in $20 \mathrm{mM}$ Tris $\mathrm{HCl}, \mathrm{pH}=8.0$ and was kept on ice. A freshly thawed tube of L-ASA solution was neutralized with cold $1 \mathrm{M} \mathrm{NaHCO}_{3}$ and quickly added to reaction mixture to an approximate concentration of 10 mM L-ASA. To establish a baseline measurement, $700 \mu \mathrm{L}$ of the reaction mixture was immediately removed and mixed with $58 \mu \mathrm{L}$ of $16 \mathrm{M} \mathrm{H}_{2} \mathrm{SO}_{4}$, vortexed thoroughly and centrifuged at $13000 \mathrm{~g}$ for 3 minutes. The remaining reaction mixture was placed in $37^{\circ} \mathrm{C}$ water bath for 20 minutes. Following this incubation, $700 \mu \mathrm{L}$ of the mixture was removed, acidified and centrifuged in the same manner. The supernatant of both pre and post reaction samples were extracted with $3 \mathrm{~mL}$ diethyl ether. One milliliter of the extract in ether layer was immediately placed into a $1 \mathrm{~mL}$ quartz cuvette and the absorbance at $269 \mathrm{~nm}$ was determined for rapid estimation of DPA production. The dried sample was then resuspended in $150 \mu \mathrm{L} 0.01 \%$ formic acid and DPA was quantified by mass spectrophotometry using MRM. In order to assay for the activity of DPA synthase in recombinant BL21-CodonPlus-RIL E. coli, the reaction mixture contained $2 \mathrm{mg}$ B. subtilis 168 sporulating crude cell extract protein as a source of DHDPA synthase was used. In order to confirm the direct interaction between DHDPA synthase and fixA and fixB proteins for DPA formation in vitro, a $1.5 \mathrm{~mL}$ reaction mix containing L-ASA and pyruvate was placed into a dialysis chambers with a $3.5 \mathrm{kDa}$ molecular weight cut-off separated this reaction from a $1.5 \mathrm{~mL}$ chamber containing only fixA and fixB. Both chambers contained $20 \mathrm{mM}$ Tris buffer at $\mathrm{pH}$ $=8.0$. To facilitate the diffusion of molecules across the membrane, the reaction time was lengthened to 1 hour.

\section{Results}

On the basis of microscopic and spore -staining data, it appears that the species of genus Mycobacterium undergoes sporulation in late stationary phase. If sporulation turns out to be a common mechanism used by mycobacteria in response to environmental conditions, it can be speculated that it might well be one the means by which it attains dormancy within the host. In this study expression of fixA and fixB genes was studied on possible formation of dipicolinic acid in $M$. marinum CCUG 20988. Figure 1 shows the alignment of fixA and fixB genes in M. marinum genome. Figure $2 \mathrm{~A}, 2 \mathrm{~B}$ shows amplification of fixB gene using $M$. marinum CCUG 20988 genomic DNA with FP1101, FP1102, FP0942 and FP0943 external primers, respectively. As shown in the picture lanes, 2 to 8 are colony PCR for fixB gene which is approximately $1000 \mathrm{bp}$ according to $1 \mathrm{~kb}$ DNA ladder.

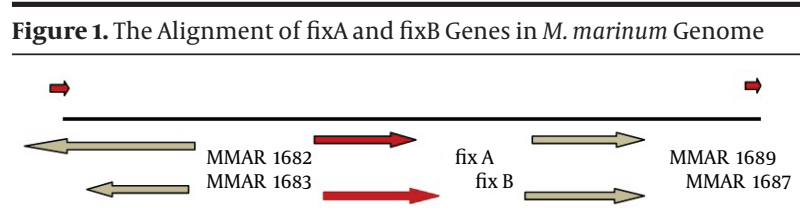

The locus tag of fixA and fixB are MMAR1684 and MMAR1685, respectively.
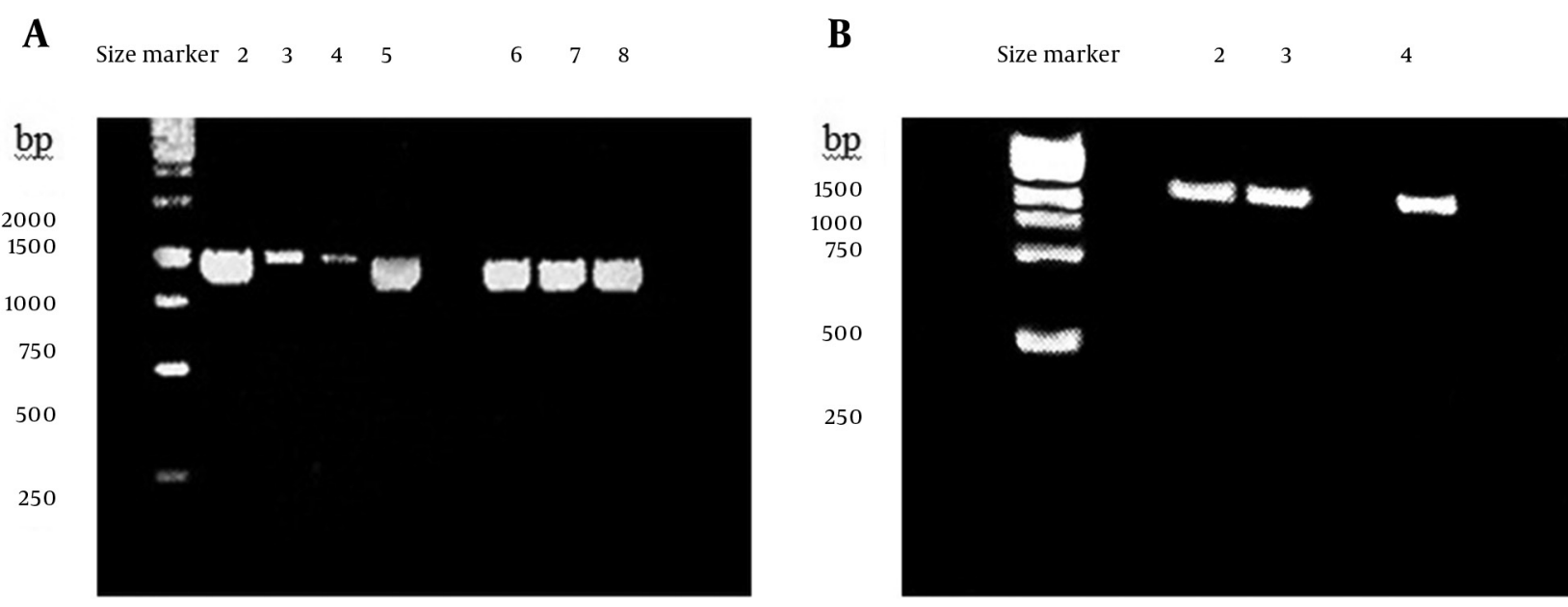

Figure 2. Amplification of fixB Gene Using M. marinum CCUG 20988 Genomic DNA With FP1101, FP1102 (Figure 2 A, Lanes 2-8), and With FP0942 and FP0943 External Primers (Figure 2 B, Lanes 2-4) 
The same pattern was confirmed with external primers (Figure $2 \mathrm{~B}$ ). Figure 3 shows the amplification of fixA and fixB genes separately and using fixA forward primer and fixB reverse primers. According to DNA size marker, the amplified fixA, fixB and fix A and fixB genes were $800 \mathrm{bp}$, $1000 \mathrm{bp}$ and $1800 \mathrm{bp}$ according to $1 \mathrm{~kb}$ DNA ladder, respectively.

The results of DPA formation in recombinant BL21-CodonPlus-RIL E. coli containing, fixB, fixA and fixB together and pknB genes upon insertion of pET19b vector and induction with IPTG were summarized in Tables 1 and 2. As shown there is no significant difference in DPA formation detected using fixB alone fixA and fixB together in the host strain in LB medium (Table 1). But detectable DPA formation has been identified upon IPTG induction in LB and M9 minimal media. DPA formation in M9 minimal media was more than LB medium (Table 2).

Synthesis of dipicolinic acid occurs in the lysine biosynthetic pathway; it can be concluded that lysine could play as an inhibitor for DPA formation, when it is present in the medium such as Luria broth. Expression of fixA, fixB and genes in cell extracts of BL21-CodonPlus-RIL E. coli was shown in SDS-PAGE (Figure 4), revealing the presences around 15 protein. The fraction containing fixA, fixB proteins upon induction by IPTG, migrated on native gel with an approximately 80 and $100 \mathrm{KDa}$, respectively. The pknB gene did not induce by using IPTG because it controls negatively. Also, over expression of fixA, fixB and both of these genes were provided in Figure 5. As shown in the Figure 5, the approximate molecular weight of fixA,
fixB and both of the proteins are about 80,100, and 180 $\mathrm{KDa}$, respectively. To determine if DPA is made in M. marinum, we used a biochemical assay for the DPA synthase. The assay included L-ASA pyruvate and a source of DHDPA synthase activity. Vegetative cell lysates did not show any color development whereas the presence of spores showed an increasing intensity of color in proportion to the amount of spore particles in suspension. The vitro system which we used for in vitro study of DPA formation showed that the products of both fixA, fixb genes are able to form dipicolinc acid in M. marinum T CCUG 20988.

Figure 3. Amplification of fixA and fixB Gene Using M. marinum CCUG 20988 Genomic DNA

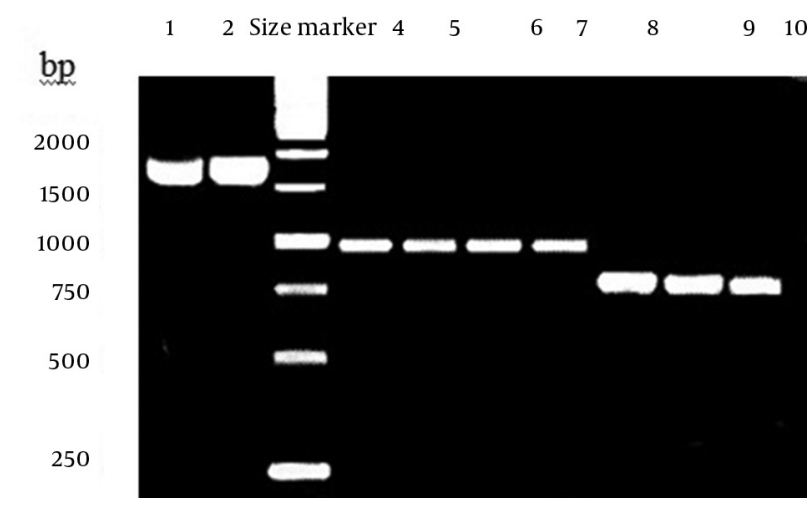

Both fixA and fixB (Lanes 1-2), fixB (Lanes 4-7) and fixA (Lanes 8-10)

Table 1. Measurement of DPA in Host Strain E. coli BL21/pET19b Containing fixA, fixB and PknB Genes a

\begin{tabular}{lcccc}
\hline & $\begin{array}{c}\text { E. coli BL21/pET19b, } \\
\text { fixB }\end{array}$ & $\begin{array}{c}\text { E. coli BL21/pET19b, } \\
\text { fixA and fixB }\end{array}$ & $\begin{array}{c}\text { E. coli BL21/pET19b, } \\
\text { PknB }\end{array}$ & $\begin{array}{c}\text { Bacillus subtilis 168 } \\
\text { Overnight culture }\end{array}$ \\
\hline $\begin{array}{l}\text { Dipicolinic acid concentration in } \\
\text { LB medium, } \mu \mathrm{g} / \mathbf{m L}\end{array}$ & $19.5 \pm 0.37$ & $22.5 \pm 0.49$ & - & $125.3 \pm 1.21$ \\
\hline
\end{tabular}

${ }^{\mathrm{a}}$ Data are presented as Mean \pm SD.

Table 2. Measurement of DPA in Host strain E. coli BL21/pET19b Containing fixA, fixB and PknB Genes Uninduced and Induced With IPTG $^{\mathrm{a}}$

\begin{tabular}{|c|c|c|c|c|c|c|}
\hline & $\begin{array}{l}\text { E. coli BL21/ } \\
\text { pET19b } \\
\text { (fixB) Unin- } \\
\text { duced }\end{array}$ & $\begin{array}{l}\text { E. coli BL21/ } \\
\text { pET19b } \\
\text { (fixB) IPTG- } \\
\text { Induced }\end{array}$ & $\begin{array}{c}\text { E. coli BL21/ } \\
\text { pET19b (fixA } \\
\text { and fixB) Un- } \\
\text { induced }\end{array}$ & $\begin{array}{c}\text { E. coli BL21/ } \\
\text { pET19b (fixA } \\
\text { and fixB) IPTG- } \\
\text { Induced }\end{array}$ & $\begin{array}{c}\text { E. coli BL21/ } \\
\text { pET19b } \\
\text { (PKnB) IPTG- } \\
\text { Uninduced }\end{array}$ & $\begin{array}{c}\text { E. coli BL21/ } \\
\text { pET19b (PKnB) } \\
\text { IPTG- IPTG- } \\
\text { induced }\end{array}$ \\
\hline $\begin{array}{l}\text { Dipicolinic acid concen- } \\
\text { tartion I LB medium, } \\
\mu \mathrm{g} / \mathrm{mL}\end{array}$ & $21.6 \pm 0.44$ & $26.3 \pm 0.32$ & $24.5 \pm 0.61$ & $32.8 \pm 0.73$ & - & - \\
\hline $\begin{array}{l}\text { Dipicolinic acid concen- } \\
\text { tartion in } \mathrm{M9} \text { minimal } \\
\text { medium, } \mu \mathrm{g} / \mathrm{mL}\end{array}$ & $23.8 \pm 0.39$ & $28.7 \pm 1.04$ & $29.3 \pm 1.34$ & $49.2 \pm 1.62$ & - & - \\
\hline
\end{tabular}

\footnotetext{
a Data are presented as Mean \pm SD.
} 
Figure 4. SDS-Polyacrylamide gel Electrophoresis of Over Expression of fixA and fixB Genes in Cell Extracts of BL21-CodonPlus-RIL E. coli

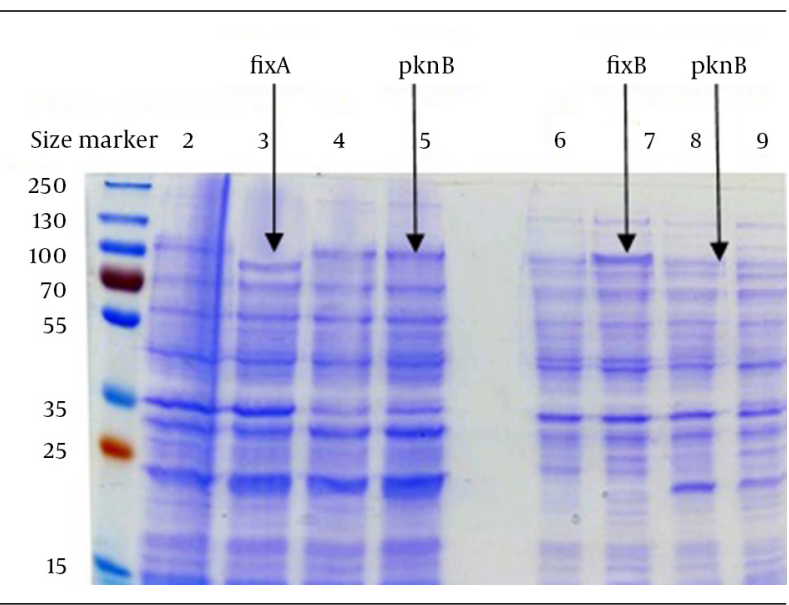

Lane 2, cell extract for fixA uniduced with IPTG, Lane 3, cell extract for fixA induced with IPTG. Lane 4, cell extract for pknB uniduced with IPTG, Lane 5 , and cell extract for pknB induced with IPTG. Lane 5, cell extract for fixB uniduced with IPTG and Lane 6, cell extract for fixB induced with IPTG. Lane 8, cell extract for pknB uniduced with IPTG, Lane 9, and cell extract for pknB induced with IPTG.

Figure 5. SDS-Polyacrylamide Gel Electrophoresis of over Expression of fixA and fixB Genes in Cell Extracts of BL21-CodonPlus-RIL E. coli

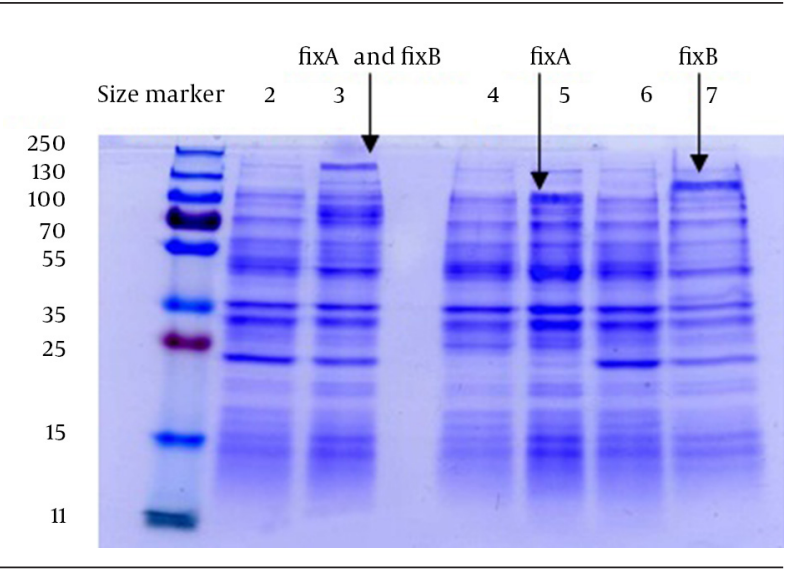

Lane 2, cell extract for fixA and fixB uniduced with IPTG, Lane 3, and cell extract for fixA and fixB induced with IPTG. Lane 4, cell extract for fixA uniduced with IPTG, Lane 5, cell extract for fixA induced with IPTG. Lane 6, cell extract for fixB uniduced with IPTG and Lane 7, cell extract for fixB induced with IPTG

\section{Discussion}

In this study we explored if the fixA and fixB genes which are electron transfer flavoproteins may incorporate in DPA formation in $M$. marinum T CCUG 20988. The obtained results showed that fixA and fixB together are able to form detectable DPA around $33(\mu \mathrm{g} / \mathrm{mL})$ in host strain upon IPTG induction in LB and M9 minimal media. It seems that DPA formation in genus Mycobacteria is similar to genus Clostrida using an electron transfer flavoprotein. We assume that if sporulation turns out to be a common mechanism used by mycobacteria in response to environmental conditions, it might be one of the means by which it attains dormancy within the host. This finding opens up a new hitherto to the unknown area of high $\mathrm{G}+\mathrm{C}$ percent of Gram positive bacteria such as Mycobacteria. This finding is consistent with Ghosh et al. [7]. They could detect dipicolinic acid in M. marinum cells of different ages using colorimetric assay method suggested by Janssen et al. [10]. Unlike low G+C percent Gram positive bacteria, sporulation in Mycobacteria is not a frequent property and needs to be investigated more, for example finding homologous genes of spore formation.

Previously in vitro studies in which DPA was detected by absorbance methods suggested that DPA might form spontaneously from DHDPA at high $\mathrm{pH}$ [12-15]. But, recently Orsburn et al. [12] reported that an electron transfer flavoprotein, EtfA catalyzes the formation of dipicolinic acid in Clostridium perfringens. They indicated that besides DHDPA synthase, DPA synthase is required for rapid DPA production. Also, they showed that whole-cell extract of $C$. perfringenes NCTC 8679, a strain shown to produce spore with significant amount of DPA, indicated that DPA synthase activity in this strain was greatest 11 hours after inoculation into DSSM medium. Based on the work provided by Ghosh et al. [7] and presence of some evidence in sporulation in laboratory cultures of the mycobacterial strain such as M. marinum, M. bovis bacillus Calmette-Guerin strain, finding new evidences to support this claim is important.

\section{Acknowledgements}

We would like to thank vice-presidency of research affairs of Islamic Azad University-Lahijan Branch and vicepresidency of research affairs of Islamic Azad UniversityCentral Office. Also, we would like to thank Department of Cell and Molecular Biology-Uppsala University for providing facilities during this project. This work was supported by Grants no. 23152 from the Swedish Foundation for Strategic Research to (L.A.K).

\section{Authors' Contributions}

All authors had equal role in design, work, statistical analysis, and manuscript writing.

\section{Funding/Support}

Swedish Foundation for Strategic Research to (L.A.K).

\section{References}

1. Paidhungat M, Setlow B, Driks A, Setlow P. Characterization of spores of Bacillus subtilis which lack dipicolinic acid. J Bacteriol. 2000;182(19):5505-12.

2. Szulmajster J, Bonamy C, Laporte J. Isolation and properties of a temperature-sensitive sporulation mutant of Bacillus subtilis. $J$ Bacteriol.1970;101(3):1027-37.

3. Daniel RA, Errington J. Cloning, DNA sequence, functional analysis and transcriptional regulation of the genes encoding dipicolinic acid synthetase required for sporulation in Bacillus subtilis. J Mol Biol. 1993;232(2):468-83. 


\section{Faezi Ghasemi M et al.}

4. Yugari Y, Gilvarg C. The condensation step in diaminopimelate synthesis. J Biol Chem. 1965;240(12):4710-6.

5. Boughton BA, Dobson RC, Gerrard JA, Hutton CA. Conformationally constrained diketopimelic acid analogues as inhibitors of dihydrodipicolinate synthase. Bioorg Med Chem Lett. 2008;18(2):460-3.

6. Bach ML, Gilvarg C. Biosynthesis of dipicolinic acid in sporulating Bacillus megaterium. J Biol Chem. 1966;241(19):4563-4.

7. Ghosh J, Larsson P, Singh B, Pettersson BM, Islam NM, Sarka SN, et al. Sporulation in mycobacteria. Proc Natl Acad Sci U S A. 2009;106(26):10781-6.

8. Flardh K, Buttner MJ. Streptomyces morphogenetics: dissecting differentiation in a filamentous bacterium. Nat Rev Microbiol. 2009;7(1):36-49.

9. Traag BA, Driks A, Stragier P, Bitter W, Broussard G, Hatfull G, et al. Do mycobacteria produce endospores? Proc Natl Acad Sci U S A. 2010;107(2):878-81.

10. Janssen FW, Lund AJ, Anderson LE. Colorimetric assay for dipico- linic acid in bacterial spores. Science. 1958:127(3288):26-7.

11. Black S, Wright NG. beta-Aspartokinase and beta-aspartyl phosphate. J Biol Chem.1955;213(1):27-38.

12. Orsburn BC, Melville SB, Popham DL. EtfA catalyses the formation of dipicolinic acid in Clostridium perfringens. Mol Microbiol. 2010;75(1):178-86.

13. Kimura K. Pyridine-2,6-dicarboxylic acid (dipicolinic acid) formation in Bacillus subtilis. I. Non-enzymatic formation of dipicolinic acid from pyruvate and aspartic semialdehyde. J Biochem. 1974;75(5):961-7.

14. Kimura K, Sasakawa T. Pyridine-2, 6-dicarboxylic acid (dipicolinic acid) formation in Bacillus subtilis. II Non-enzymatic and enzymatic formations of dipicolinic acid from alpha, epsilondiketopimelic acid and ammonia. J Biochem. 1975;78(2):381-90.

15. Rivera MC, Jain R, Moore JE, Lake JA. Genomic evidence for two functionally distinct gene classes. Proc Natl Acad Sci U S A. 1998;95(11):6239-44. 